JURNAL SEHAT MASADA VOLUME XIV NOMOR 2 Juli 2020 ISSN : 1979-2344

\title{
CHRONIC SORROW DAN QUALITY OF LIFE PADA PASIEN DENGAN DIABETIC FOOT ULCER (DFU)
}

\author{
Putri Puspitasari ${ }^{1}$ \\ Program Studi Sarjana Keperawatan STIKes Dharma Husada Bandung \\ putripuspitasari@stikesdhb.ac.id
}

\begin{abstract}
ABSTRAK
Pendahuluan : Diabetic Foot Ulcer (DFU) merupakan komplikasi jangka panjang yang umum ditemukan pada pasien Diabetes Mellitus (DM). Penurunan kualitas kesehatan, proses penyembuhan yang lambat, ancaman amputasi, serta ancaman kematian berdampak terhadap keadaan psikologis yang buruk bagi penderita DFU. Keadaan emosi yang mungkin timbul pada pasien dengan penyakit kronis seperti DFU adalah perasaan chronic sorrow dan Quality Of Life yang kurang baik. Tujuan dari penelitian ini adalah melihat keadaan chronic sorrow dan quality of life pada pasien dengan DFU serta secara spesifik melihat hubungan antara chronic sorrow dengan quality of life pasien dengan DFU

Metode Penelitian: Penelitian ini merupakan jenis penelitian kuantitatif dengan desain analytic correlative dan rancangan penelitian menggunakan pendekatan cross sectional study. Tujuan penelitian ialah untuk menganalisis hubungan antara chronic sorrow dan kualitas hidup pada pasien dengan DFU. Sampel penelitian adalag 46 Responden.

Hasil dan kesimpulan: hasil penelitian menunjukan dari 46 responden $29(63,04 \%)$ mengalami keadaan chronic sorrow dan diantara 46 responden 27 (58,7\%) mengalami keadaan kualitas hidup yang kurang baik. Responden yang mengalami chronic sorrow memiliki kualitas hidup yang kurang baik sebesar 78,13\% dan kualitas hidup yang baik sebesar 21,87 \% dengan p= 0,000 lebih kecil dari $\alpha=0,05$, yang dapat diartikan bahwa terdapat hubungan bermakna antara keadaan chronic sorrow dan quality of life.
\end{abstract}

Kata Kunci : Diabetic Foot Ulcer (DFU), Chronic Sorrow, Quality Of Life

\section{PENDAHULUAN}

Diabetic Foot Ulcer (DFU) merupakan komplikasi jangka panjang yang umum ditemukan pada pasien Diabetes Mellitus (DM). Diperkirakan 6,9\% penduduk Indonesia mengalami DM (Kruse, Ingrid \& Edelman, 2006), dan diperkirakan 25\% dari penderita DM mengalami DFU (Iversen, dkk, 2009). Sehingga dapat diperkirakan jika jumlah penduduk Indonesia saat ini adalah 267,7 juta jiwa, maka yang menderita DM adalah 18,42 juta jiwa dan yang mengalami DFU adalah 4,6 juta jiwa.

DFU sebagai komplikasi menahun yang paling ditakuti bagi penderita DM seringkali menimbulkan dampak bagi penderitanya. Penurunan kualitas kesehatan dirasakan pasien dengan DFU terutama karena gangguan mobilitas dan rasa nyeri serta ketidaknyamanan yang dirasakan (Siersma, 2013). Keadaan ini diperburuk oleh proses penyembuhannya yang lama. Hasil penelitian yang dilakukan Oibo (2001) tercatat sebanyak 65\% pasien dengan DFU sembuh sepenuhnya selama, $16 \%$ tidak sembuh, 15,5\% mengalami amputasi, dan 3,5\% meninggal dunia dengan rata-rata waktu penyembuhan 10 minggu, penelitian dilakukan selama 6 bulan. 
Penurunan kualitas kesehatan, proses penyembuhan yang lambat, ancaman amputasi, serta ancaman kematian berdampak terhadap keadaan psikologis yang buruk bagi penderita DFU (Inversen, 2009; Beattie, dkk, 2014). Keadaan emosi negatif timbul berupa perasaan marah, takut, depresi, dan hilangnya harga diri akan berdampak buruk pada gaya dan kualitas hidup pasien (Beattie, 2014; Vileikyte, 2001). Keadaan emosi lain yang mungkin timbul pada pasien dengan penyakit kronis seperti DFU adalah perasaan chronic sorrow (Ahlstrom, 2007). Chronic sorrow merupakan perasaan bersedih karena kehilangan yang terjadi karena adanya perbedaan antara harapan atau keinginan dengan kenyataan yang terjadi (Alligood, 2010).

Beberapa penelitian dilakukan untuk mengidentifikasi bagaimana gambaran chronic sorrow pada pasien dengan penyakit kronik. Ahlstrom Gerd (2007) melakukan penelitian tentang bagaimana gambaran chronic sorrow dan perasaan kehilangan pada pasien penyakit kronik. Hasilnya $73 \%$ subjek pernah mengalami chronic sorrow. Didapatkan subjek yang mengalami chronic sorrow mengalami kehilangan berupa hilangnya fungsi tubuh, hilangnya hubungan sosial, hilangnya fungsi otonom dan kehilangan identitas termasuk hilangnya nilai martabat serta perubahan gambaran diri.

Ann Kristin Isaksson (2007) dalam penelitiannya menyimpulkan bahwa chronic sorrow ialah bentuk khusus dari tekanan emosional pada pasien. Penelitian tersebut menunjukkan bahwa 38 pasien (62\%) mengalami chronic sorrow dan dari jumlah tersebut 4 pasien memiliki gejala depresi ringan. Pada penelitian Lictenstein (2002) ditemukan bahwa chronic sorrow disebabkan pengalaman kehilangan, berupa hilangnya harapan, kehilangan kontrol atas tubuh dan hilangnya integritas dan martabat. Penelitian lain menunjukkan bahwa kesedihan kronis pada pasien berhubungan dengan penyakit yang dialami, ketakutan akan kematian, kemiskinan dan isolasi social, terutama pada perempuan dengan anak- anak (Lictenstein, 2002). Hal ini menjelaskan bahwa chronic sorrow akan timbul pada pasien karena adanya perasaan kehilangan (loss) dan trigger events yang terjadi pada pasien dengan penyakit kronis (Alligood, 2010; Murray J, 2016).

Studi literatur yang ditemukan, beberapa penelitian menunjukkan adanya chronic sorrow pada pasien dengan penyakit kronis seperti DFU. Chronic sorrow merupakan reaksi alami dari kehilangan yang sedang berlangsung (Murray, 2016). Chronic sorrow adalah perasaan kesedihan yang sangat mendalam. Jika tidak diatasi, chronic sorrow bersifat progresif. Chronic sorrow yang berpotensi progresif dapat menyebabkan keadaan depresi (Murray, 2016; Brodarty, 2001).

Studi literatur didapatkan $38,8 \%$ pasien DFU mengalami depresi (Methew, 2012). Berkembangnya keadaan chronic sorrow menjadi depresi akan berdampak terhadap kualitas hidup yang buruk (Vileikyte, 2001). Hal ini dipertegas oleh penelitian yang 


\section{JURNAL SEHAT MASADA VOLUME XIV}

dilakukan Ibrahim 2013, yang menunjukkan depresi merupakan faktor yang paling berhubungan dengan kualitas hidup.

Beberapa penelitian telah dilakukan untuk mengetahui bagaimana chronic sorrow pada pasien dengan penyakit kronik, tetapi pada pasien dengan DFU masih jarang dilakukan. Beberapa penelitian juga telah dilakukan untuk mengetahui bagaimana hubungan antara depresi dengan kualitas hidup pada pasien dengan DFU, tetapi bagaimana gambaran chronic sorrow dan hubungannya dengan kualitas hidup/ quality of life pada pasien dengan DFU masih jarang dilakukan. Berdasarkan fenomena tersebut, maka penulis tertarik untuk melakukan penelitian mengenai chronic sorrow dan quality of life pada pasien dengan DFU serta secara spesifik melihat hubungan antara chronic sorrow dengan quality of life pasien dengan DFU.

\section{METODE PENELITIAN}

Penelitian ini merupakan jenis penelitian kuantitatif dengan desain analytic correlative dan rancangan penelitian menggunakan pendekatan cross sectional study. Tujuan penelitian ialah untuk menganalisis hubungan antara chronic sorrow dan kualitas hidup pada pasien dengan DFU.

Populasi dalam penelitian ini adalah seluruh pasien DFU yang berkunjung ke Instalasi Rawat Inap Bedah dan Penyakit Dalam dalam RS Salamun. Pemilihan sampel dilakukan dengan teknik non probability sampling dengan pendekatan purposive
NOMOR 2 Juli 2020 ISSN : 1979-2344

sampling yaitu teknik pengambilan sampel berdasarkan pada pertimbangan tertentu yang sebelumnya ditetapkan oleh peneliti sesuai dengan kriteria inklusi dan eksklusi. ${ }^{46}$

Kriteria inklusi pada penelitian ini adalah :

1. Responden terdiagnosa DFU dengan klasifikasi Wagner $\geq 2$

2. Mampu membaca, menulis dan berbahasa Indonesia

3. Pasien DFU yang mengalami masalah kesehatan yang tidak memungkinkan untuk dijadikan responden, seperti pasien keletihan, lemah, pusing dan masalah lain Sedangkan kriteria eksklusi pada penelitian ini adalah :

1. Responden dengan gejala depresi

2. Responden yang mengundurkan diri dari penelitian sebelum penelitian selesai/ tidak mengikuti penelitian dari awal sampai akhir

Dengan menggunakan rumus perkiraan besar sampel penelitian analitis korelasi, minimal sampel yang harus didapat adalah 45 dan sampel dalam penelitian ini adalah 46 pasien. Instrumen dalam penelitian ini ialah kuesioner chronic sorrow, kuesioner kualitas hidup, dan kuesioner depresi.

\section{ANALISA DATA}

Analisa Univariat

Analisis untuk data kategorik dilakukan dengan analisis distribusi frekuensi, dalam penelitian ini adalah keadaan chronic sorrow dan Quality of life. 


\section{Analisa Bivariat}

Analisa bivariat dilakukan dalam penelitian ini untuk membuktikan hipotesa adakah hubungan antara chronoc sorrow dan quality of life pada pasien dengan DFU, dengan nilai confidence interval ditetapkan 95\% dan tingkat kemaknaan 5\% $(\alpha=0,05)$. Uji korelasi yang akan dilakukan ialah dengan Chi-square.

\section{HASIL PENELITIAN}

a. Keadaan Chronic Sorrow Pada Pasien DFU

Tabel 1 Keadaan Chronic Sorrow Pada Pasien DFU

\begin{tabular}{clcc}
\hline $\mathrm{N}$ & \multicolumn{1}{c}{$\begin{array}{c}\text { Keadaan Chronic } \\
\text { Sorrow }\end{array}$} & $\mathrm{N}=\mathbf{4 6}$ & $\%$ \\
\hline 1 & $\begin{array}{l}\text { Mengalami Chronic } \\
\text { Sorrow } \\
\text { Tidak mengalami } \\
\text { Chronic Sorrow }\end{array}$ & 32 & 69,6 \\
\hline
\end{tabular}

Berdasarkan tabel 1 didapatkan hasil bahwa dari 46 responden $29(63,04 \%)$ mengalami keadaan chronic sorrow. Dimana keadaan chronic sorrow dianalisis menggunakan kuesioner chronic sorrow.

\section{b. Quality of life pada pasien dengan DFU}

Tabel 2 Quality of life Pada Pasien DFU

\begin{tabular}{clcc}
\hline No & $\begin{array}{c}\text { Keadaan Chronic } \\
\text { Sorrow }\end{array}$ & $\mathrm{N}=46$ & $\%$ \\
\hline 1 & Kurang baik & 27 & 58,7 \\
2 & Baik & 19 & 41,3 \\
\hline
\end{tabular}

Berdasarkan tabel 2 didapatkan hasil bahwa dari 46 responden $27 \quad(58,7 \%)$ mengalami keadaan kualitas hidup yang kurang baik. Dimana keadaan kualitas hidup dianalisis menggunakan kuesioner Diabetic Foot Ulcer Scale (DFS).

\section{c. Hubungan Keadaan Chronic Sorrow dan Quality of life pada pasien dengan DFU}

Tabel 3 Chronic Sorrow dan Quality of life Pada Pasien DFU

\begin{tabular}{|c|c|c|c|c|c|c|c|}
\hline \multirow{3}{*}{$\begin{array}{l}\text { Chronic } \\
\text { Sorrow }\end{array}$} & \multicolumn{4}{|c|}{ Quality of life } & \multicolumn{2}{|c|}{ Total } & \multirow{3}{*}{$\begin{array}{l}\mathrm{p}- \\
\text { value }\end{array}$} \\
\hline & \multicolumn{2}{|c|}{ Baik } & \multicolumn{2}{|c|}{$\begin{array}{c}\text { Kurang } \\
\text { Baik }\end{array}$} & \multirow[b]{2}{*}{$\mathrm{n}$} & \multirow[b]{2}{*}{$\%$} & \\
\hline & $\mathrm{n}$ & $\%$ & $\mathrm{n}$ & $\%$ & & & \\
\hline Tidak & 12 & 85,71 & 2 & 14,29 & 14 & 100 & 0,000 \\
\hline Mengalami & & & & & & & \\
\hline Mengalami & 7 & 21,87 & 25 & 78,13 & 32 & 100 & \\
\hline Total & 27 & 100 & 19 & 100 & 46 & 100 & \\
\hline
\end{tabular}

Tabel 3 menunjukan hubungan variabel Keadaan Chronic Sorrow dan Quality of life pada pasien dengan DFU, hasil penelitian menunjukan responden yang mengalami chronic sorrow memiliki kualitas hidup yang kurang baik sebesar 78,13 \% dan kualitas hidup yang baik sebesar 21,87\% dengan $\mathrm{p}=0,000$ lebih kecil dari $\alpha=0,05$, yang dapat diartikan bahwa terdapat hubungan bermakna antara keadaan chronic sorrow dan quality of life.

\section{PEMBAHASAN}

a. Keadaan Chronic sorrow pada pasien dengan Diabetic Foot Ulcer.

Keadaan chronic sorrow seringkali dialami oleh pasien yang menderita penyakit-penyakit kronis. Pembahasan penelitian ini memfokuskan pada masalah DFU sebagai penyakit kronis yang berdampak pada keadaan chronic sorrow. Hasil penelitian didapatkan dari 46 
responden terdapat 32 responden $(69,6 \%)$ mengalami chronic sorrow.

Hasil penelitian ini tidak jauh dari hasil penelitian sebelumnya yang dilakukan oleh Ahlstrom (2010), dimana penelitian bertujuan melihat bagaimana gambaran chronic sorrow yang dilakukan pada 30 pasien dengan penyakit kronik. Penelitian tersebut menunjukkan bahwa $33 \%$ responden mengalami chronic sorrow progresif dan $73 \%$ subjek pernah mengalami chronic sorrow. Penelitian lain yang mengungkapkan angka kejadian chronic sorrow adalah penelitian yang dilakukan pada 61 pasien multiple sclerosis, hasil penelitian menunjukkan 38 pasien (62\%) mengalami chronic sorrow (Lichtenstein, 2002). Penelitian sebelumnya mendapatkan kejadian chronic sorrow pada penyakit kronik jauh lebih tinggi (antara 80\% dan 90\%) (Eakes, G.G. Burke, 1992). Terjadinya chronic sorrow pada pasien dengan penyakit kronis probabilitas dan sifat chronic sorrownya akan meningkat sesuai dengan kerugian yang harus ditanggung pasien dan tingkat keparahan penyakit fisik yang pasien alami (Alligood, 2010; Eakes, G.G. Burke, 1992).

Keadaan chronic sorrow pada pasien DFU diawali dengan adanya disparitas yang diciptakan dari pengalaman kehilangan dimana kenyataan saat ini berbeda dengan yang diinginkan. Pasien dengan DFU berharap dirinya sempurna seperti sebelumnya serta dapat bisa hidup normal, keadaan ini menyebabkan pasien DFU mengalami perasaan kehilangan. Individu dengan penyakit kronis seperti DFU akan mengalami kehilangan fungsi tubuh, emosi, sosial, kehilangan otonomi dalam diri, perubahan body image dan akhirnya akan mengalami chronic sorrow (Ahlmstrom, 2007).

Penurunan kualitas kesehatan secara langsung dirasakan pasien dengan DFU terutama karena gangguan mobilitas dan rasa nyeri serta ketidaknyamanan yang dirasakan membuat ketidakberdayaan pada pasien DFU merupakan faktor pencetus yang akan memperburuk keadaan, dimana kondisi tersebut menyebabkan penderitaan yang merupakan pemicu keadaan chronic sorrow pada pasien DFU. Penelitian lain menyebutkan kondisi chronic sorrow dapat terjadi pada individu yang mengalami masalah fisik, emosional dan sosial yang berulang, dimana kesedihan kronis ini (chronic sorrow) mempunyai sifat meluas atau menyebar (pervasive), menetap (permanent), periodik dan berpotensi progresif (potentially progressive) (Ahlstrom, 2010).

Pasien DFU juga dapat merasa kehilangan konsep diri, keadaan ini berakibat pada kondisi harga diri rendah, kehilangan ideal diri dan berimplikasi pada kondisi emosi dan pikiran yang negatif. Berdasarkan hasil penelitian pada pasien dengan DFU yang mengalami chronic sorrow, peneliti menemukan sebagaian besar pasien mengalami pasang surut emosi. 
Pasien mengungkapkan adanya pesaraan sedih, gelisah, marah, dan putus asa sehubungan dengan situasi yang dialaminya.

Pasien juga mengungkapkan adanya waktu-waktu tertentu yang cenderung membuat keadaan chronic sorrow diantaranya adalah pada saat harus mendapatkan perawatan medis, pasien merasa tegang dan takut pada saat akan dilakukan perawatan luka. Pasien juga mengungkapkan pemicu kesedihan yang lainnya adalah pada saat menyadari tanggung jawab yang dipikulnya saat ini tidak dapat dilakukan, seperti seorang ibu yang tidak dapat mengurus urusan rumah tangganya atau seorang ayah yang tidak dapat bekerja.

\section{b. Quality of life pada pasien dengan DFU}

Hasil penelitian menunjukan responden yang mengalami chronic sorrow memiliki kualitas hidup yang kurang baik sebesar $78,13 \%$ dan kualitas hidup yang baik sebesar 21,87 \%. Pasien dengan DFU seringkali mengeluhkan tentang keterbatasan dalam mobilitas dan memerlukan adaptasi terhadap gaya hidup yang berbeda. Penelitian sebelumnya juga menunjukkan bahwa DFU memiliki dampak yang signifikan terhadap kualitas hidup. Ulkus diabetik menyebabkan hilangnya mobilitas yang dapat mempengaruhi kemampuan pasien dalam melakukan gerakan sederhana, tugas sehari-hari serta berpartisipasi dalam seluruh kegiatan (Khaledian M, 2013).
Kondisi ini senada dengan data di Amerika Serikat, bahwa $60-70 \%$ penderita diabetes melitus yang mengalami ulkus diabetik dikaki yang menyebabkan penurunan aktivitas (Kanine, E, 2011).

Kualitas hidup mereka juga dipengaruhi oleh adanya nyeri karena DFU serta adanya gangguan mobilitas. Kesehatan fisik pasien yang mengalami ulkus diabetik berada pada kategori kurang baik disebabkan karena kondisi sakit yang mereka alami dan kelelahan menyebabkan kesulitan melakukan aktivitas. Selain itu, nyeri pada ulkus juga menyebabkan pola tidur mereka yang terganggu, sehingga seringkali mengeluhkan tidak puas terhadap kualitas tidur. Semua hal ini menyebabkan para responden tidak merasa puas dengan kesehatan mereka (Sarfika R, 2012, ; Cornelia, Sumedi E, 2013).

Penelitian-penelitian tentang kualitas hidup menunjukkan kualitas hidup seseorang yang menderita diabetes lebih rendah dari pada orang yang tidak menderita diabetes. Komplikasi ulkus diabetik sangat mempengaruhi serta memberi efek negatif besar terhadap kualitas hidup seseorang. Studi kualitatif telah menunjukkan bahwa ulkus diabetik memberi efek negatif psikologis dan sosial yang besar diantaranya pengurangan kegiatan sosial, meningkatkan ketegangan untuk keluarga pasien termasuk pengasuh atau mitra, kerja yang terbatas dan kesulitankeuangan. 
Penelitian lain menunjukan hasil yang berbeda, penelitian terhadap 61 pasien multiple sclerosis menunkukan bahwa tidak ada hubungan antara chronic sorrow dan quality of life pada pasien yang mengalami multiple sclerosis. Peneliti menyimpilkan bahwa chronic sorrow adalah perasaan bersedih yang merupakan reaksi alami dari kehilangan yang sedang berlangsung, keadaan ini biasanya tidak mengganggu fungsi kehidupan sehari-hari. Namun, chronic sorrow adalah perasaan kesedihan yang sangat mendalam, jika terdapat suatu pemicu chronic sorrow akan muncul kembali dan jika tidak diatasi chronic sorrow dapat bersifat permanen, berkala, dan berpotensi progresif (Lichtenstein, 2002). Asumsi peneliti, perbedaan hasil penelitian terjadi karena responden penelitian memiliki karakteristik penyakit dan gejala yang yang berbeda.

\section{c. Hubungan Keadaan Chronic Sorrow dan Quality of life pada pasien dengan DFU}

Hasil penelitian menunjukan responden yang mengalami chronic sorrow memiliki kualitas hidup yang kurang baik sebesar $78,13 \%$ dan kualitas hidup yang baik sebesar $21,87 \%$ dengan $\mathrm{p}=0,000$ lebih kecil dari $\alpha=0,05$, yang dapat diartikan bahwa terdapat hubungan bermakna antara keadaan chronic sorrow dan quality of life.

Hasil ini sejalan dengan penelitian sebelumnya, penelitian ini dilakukan dilakukan pada 47 orang responden ulkus diabetik di kaki. Hasil penelitian menunjukkan bahwa kesehatan psikologis mempengaruhi kualitas hidup para penderita ulkus diabetik. Penderita ulkus diabetic seringkali merasa khawatir terhadap penyakit, sehingga menghambat mereka beraktivitas. Rasa cemas sangat mempengaruhi kesehatan psikologis seseorang yang menderita ulkus diabetic. Rasa cemas meningkat karena kekhawatiran akan luka yang tidak akan sembuh, perasaan kehilangan motivasi untuk bangkit, hilangnya kebebasan, dan frustasi karena menjadi beban bagi keluarga, serta ketakutan akan diamputasi I (Oliver, 2007).

Respon kehilangan merupakan penyebab keadaan chronic sorrow. Pasien dengan DFU berharap dirinya sempurna seperti sebelumnya serta bisa hidup normal, keadaan ini menyebabkan pasien DFU mengalami perasaan kehilangan. Pasien dengan DFU memiliki masalah gangguan mobilitas, nyeri kaki, merasa lemas untuk melakukan aktifitas, susah tidur, dan hilang napsu makan, mudah lupa dan sulit berkonsentrasi. Keadaan ini menyebabkan klien mudah marah dan tersinggung, merasa cemas, merasa bersedih, merasa merepotkan keluarganya, tidak percaya diri dengan bentuk tubuh (kaki) yang sekarang, merasa menjadi beban keluarga serta merasa putus asa untuk kembali sembuh (Oliver, 2007).

Keadaan ini sesuai dengan teori yang dikemukakan, ketika sebuah peristiwa atau situasi memicu kesedihan kronis, seseorang 


\section{JURNAL SEHAT MASADA VOLUME XIV}

akan menunjukkan gejala yang serupa dengan depresi termasuk kesedihan, kemarahan, frustrasi, serta rasa bersalah yang mendalam, hal inilah yang menyebabkan pasien dengan chronic sorrow mengalami kualitas hidup yang kurang baik (Eakes, Burke, 2002).

Penelitian lain menyebutkan kondisi chronic sorrow dapat terjadi pada individu yang mengalami masalah fisik, emosional dan sosial yang berulang, dimana kesedihan kronis ini (chronic sorrow) mempunyai sifat meluas atau menyebar (pervasive), menetap (permanent), periodik serta berpotensi progresif (potentially progressive) (Ahlmstrom, 2007). Dimana chronic sorrow yang bersifat progressive dapat mengarah ke keadaan depresi, serta keadaan depresi sangat berkaitan dengan kualitas hidup pasien DFU yang kurang.

Pasien DFU juga dapat merasa kehilangan konsep diri yang berakibat pada kondisi harga diri rendah, kehilangan ideal diri dan berimplikasi pada kondisi emosi dan pikiran yang negatif. Berdasarkan hasil penelitian pada pasien dengan DFU yang mengalami chronic sorrow, peneliti menemukan sebagaian besar pasien mengalami pasang surut emosi. Pasien mengungkapkan adanya pesaraan sedih, gelisah, marah, dan putus asa sehubungan dengan situasi yang dialaminya saat ini.
NOMOR 2 Juli 2020 ISSN : 1979-2344

\section{KESIMPULAN}

1. Keadaan chronic sorrow, dari 46 responden $29 \quad(63,04 \%)$ mengalami keadaan chronic sorrow.

2. Keadaan quality of life, dari 46 responden $27(58,7 \%)$ mengalami keadaan kualitas hidup yang kurang baik.

3. Hasil uji statistik juga didapatkan terdapat hubungan yang signifikan antara chronic sorrow dan quality of life pada pasien dengan DFU.

\section{DAFTAR PUSTAKA}

Ahlstrom G. 2007. Experiences of loss and chronic sorrow in persons with severe chronic illness. J Clin Nurs.;16(3 A):7683.

Alligood M. 2010. Nursing Theory And Their Work. USA: Mosby Elsevier.

Beattie AM, Campbell R, Vedhara K. 2014. "What ever I do it"s a lost cause.' The emotional and behavioural experiences of individuals who are ulcer free living with the threat of developing further diabetic foot ulcers: A qualitative interview study. Heal Expect.17(3):42939.

Brodarty. 2016. Understanding Loss: A Guide for Caring for Those Facing Adversitytle. London and New York: routledge;. 69-70 p.

Eakes, G.G. Burke, M. L. \& Hainswoth MA. 1998. Middle range theory of chronic sorrow. J Nurs Scholarsh ;30(2).

Ibrahim. 2013. Analisis faktor-faktor yang mempengaruhi kualitas hidup pasien ulkus diabetikum $=$ Analysis of factors affecting quality of life patients with diabetic ulcer. Jakarta: Tesis UI 
Iversen MM, Midthjell K, Tell GS, Moum T, Ostbye T, Nortvedt MW, et al. 2009. The association between history of diabetic foot ulcer, perceived health and psychological distress: the NordTrondelag Health Study. BMC Endocr Disord;9:18.

Kanine, E., Helena N.C.D. NT. 2011. Pengaruh logoterapi individu terhadap respon ketidakberdayaan klien diabetes mellitus di RS Provinsi Sulawesi Utara. Jakarta: Tesis UI.

Khaledian M, Parvaz R, Garosi MR, Habibzade S. 2013. The Effectiveness of Logo Therapy on the Rise of Hopefulness in Empty-Nest Syndrome. Int J Basic Sci Appl Res;2(3):354-8.

Kruse, Ingrid \& Edelman S. 2006. Evaluation and Treatment of Diabetic Foot Ulcers. Clin Diabetes;24(2):91-3

Lichtenstein Bronwen, Ph.D., Laska Mary K, Ph.D, Clair Jeffrey M PD. 2002. Chronic Sorrow in the HIV-Positive Patient : Issues of Race, Gender, and Social Support. AIDS Patient Care STDS.;16(1).

Methew, C.S., Dominic, M., Isaac, R., Jacob J. 2012. Prevalence of depression in consecutive patients with diabetes mellitus of 5 years duration and its impact on glycemic control. Indian $\mathrm{J}$ Endocrinol Metab.;16:5.

Murray J. 2016. Understanding Loss: A Guide for Caring for Those Facing Adversitytle. London and New York: routledge;. $69 \mathrm{p}$.

Oliver R Herber, Wilfried Schnepp, Monika A Rieger. 2007. A systematic review on the impact of leg ulceration on patients quality of life. Health and Quality of Life Outcomes. 5:44 doi:10.1186/1477-7525-544

Oyibo SO, Jude EB, Tarawneh I, Nguyen HC, Armstrong DG, Harkless LB, et al. 2001. The effects of ulcer size and site, patient's age, sex and type and duration of diabetes on the outcome of diabetic foot ulcers. Diabet Med.18(2):133-8

Sarfika R. 2012. Pengaruh terapi kognitif dan logoterapi terhadap depresi, ansietas, kemampuan mengubah pikiran negatif dan memaknai hidup klien diabetes mellitus. Jakarta: Tesis UI;.

Siersma V, Thorsen H, Holstein PE, Kars M, Apelqvist J, Jude EB, et al. 2013. Importance of factors determining the low health-related quality of life in people presenting with a diabetic foot ulcer: The Eurodiale study. Diabet Med.;30(11):1382-7.

Vileikyte L. 2001. Diabetic foot ulcers: a quality of life issue. Diabetes Metab.17(4):246-9. 